\title{
The Peril of Milk.
}

\section{By Prof. Henry E. Armstrong.}

A

CONFERENCE of a most important and serious character was held in the Council Chamber of the Guildhall, London, on October $16-18$, during the week of the Dairy Show, dealing with our milk supply in practically all its aspects-except the scientific! Yet we speak of science as salvation, perpetually proclaim its importance, and deplore public apathy towards its priesthood. Our class was not invited to participate. I heard of the conference only casually and bought myself in, only at the very last moment; consequently I was relegated to a place in the gallery behind the speaker's chair, where I could not hear a word. Being unobtrusive in my ways, I descended to the floor and trespassed into a vacant seat; the platform was all but empty but no invitation to take a chair upon it came down to me. I do not wish to complain but merely point out the rewards of scientific service and the effusive way in which the man of affairs welcomes our aid.

I make this statement, indeed, just to show where we are in public esteem, when subjects of vital importance to the national welfare, with which we alone can deal effectively, are under discussion-nowhere! Whose is the fault? Our own! We are mouldering away in our laboratories and when we seek to make known what we have been doing use a jargon which we cannot ourselves understand. That we have a public duty to perform seems never to occur to us. Much of our so-called research work is very largely wasted effort, without any real intelligence behind it -without policy and without imagination. The real problems are all but untouched.

Our knowledge of milk is practically nil-this was made clear at the conference. As the result of our careless abstention from the affairs of the world, sentiment and commercialism are quietly, without hindrance, wreaking their will upon the country. Few are aware, I think, of the extent to which milk is ceasing to be milk as the cow gives it: how it is being tampered with to overcome initial avoidable carelessness, to make it keep and to satisfy the undiscriminating animus against micro-organisms engineered into existence, of late years, by bacteriologists. Apart from the wonderful livestock, the feature of the Dairy Show was Pasteurising plant. One of the most interesting of these is to be operated at $135^{\circ} \mathrm{C}$.!

I was the first to take the floor after the opening paper was read, dealing with breed of cattle in relation to quantity, composition and cost of milk production. I deplored the absence of the chemist and insisted that we know nothing of the composition of milk in any proper sense of the term-that to talk of it in terms of fat and solids-not-fat was equivalent to describing a house in terms of percentages of bricks, mortar, wood, etc. Modern discovery had taught us that the essential value of milk lay in certain mysterious minor constituents which could neither be identified nor quantified-yet were of most vital consequence: which I would term advitantsto catch the public ear, maybe vitalites were betterbut refuse to misname vitamins.

To justify Pasteurisation, we have to show that no harm is done to milk by heating it above bloodheat. To heat it above this temperature is to treat it unnaturally-this cannot be gainsaid. That it is altered thereby is proved up to the hilt. The contention is that, by making a certain addition, we can compensate for the alteration-but we have only superficial evidence in favour of this contention. The medical profession has only recently had its attention directed to these matters-it does not know yet what to look for. The effects may be deep-seated, we know; and they may come but slowly under notice. Time alone, combined with the most refined study of the problem, can prove that it is safe to trespass beyond Nature's limit. The second teeth, we know, are formed at birth; scurvy affects their structure ere change be noticeable externally; and so it may be in other cases. The bad teeth of our nation are probably, at least in large part, due to defective nutrition in early years and they affect us throughout life. Nations whose children are all breast-fed have good teeth.

The only rational assumption to make is that no constituent of milk is without a purpose and that, if anything in it be destroyed, it loses in dietetic value. The recent remarkable discovery, that a something secreted by the pancreas, no gross constituent apparently, is required for the normal metabolism of so combustible an article of diet as sugar, should be a warning against destroying any natural agent in a whole food like milk; especially in view of recent work by Gowland Hopkins.

At a time when we are beginning to know these things, we have no right to develop an unnatural practice and allow it to become general. We must gain much more knowledge before making up our minds. On all sides, at the conference, it was recognised that clean raw milk can be produced and purveyed, if we will but take a little care.

Scurvy, rickets, beriberi, we know, are diseases affecting us as consequences of malnutrition ; scurvy became rife in Denmark early in the war, on the farms, when the children were fed on Pasteurised milk. Who shall say that a host of our minor complaints are not due to dietetic deficiencies? Women are often most faddy feeders and the frequent appearance of nervous disorders in their sex may well be connected with lack of vital elements, even due to seed sown in infancy. We may be laying the foundation of complaints worse than cancer.

Who knows or does not know? At present we can assert nothing, either way, so crass is our ignorance : so let us halt while we may.

The effect of food on the cow's milk was more than once brought out at the meetings. We were told that milk from cows that had been stall-fed but grazed occasionally proved vastly richer in one of the advitants than that from animals simply stall-fed; also that two varieties of one root crop had different effects on the production of milk. Pigs apparently give healthy pork when grass-fed but not when starved of green food. The whole field of food inquiry lies open before us. Prof. Stenhouse Williamsdairy bacteriologist at Reading College-and I were the only speakers to sound the note of nutritional danger from Pasteurisation. We stood alone. Rothamsted, which claims to stand at the head of agricultural research, was unheard; the Animal Nutrition station at Cambridge was voiceless. Sir W. Morley Fletcher, of the Medical Research Council, who took the chair at the discussion on Pasteurisation, had not a word to say by way of caution. The Medical Research Council, however, has never had a chemist among its members; and yet medicine is nothing but applied chemistry.

Where, we may ask, are the Prophets ? Science is simply disgracing itself in this matter of milk: the call to wake up and defend the public health must go out everywhere. 